\title{
Expression of Concern: Application and economic viability of wind turbine installation in Lutak, Iran
}

\author{
Kasra Mohammadi ${ }^{1} \cdot$ Ali Mostafaeipour $^{2} \cdot$ Ahmad Sedaghat $^{3} \cdot$ Shahaboddin Shamshirband $^{4} \cdot$ Dalibor Petković $^{5}$
}

Published online: 19 December 2018

c) Springer-Verlag GmbH Germany, part of Springer Nature 2018

\section{Expression of Concern: \\ Environ Earth Sci (2016) 75:248 \\ https://doi.org/10.1007/s12665-015-5054-7}

The Editors-in-Chief of Environmental Earth Sciences are issuing an editorial expression of concern to alert readers that this article (Mohammadi et al. 2016) shows substantial indication of irregularities in authorship during the submission process. The authors suggested peer reviewers whose identity was not possible to verify. This article contains overlap with (Mostafaeipour and Mohammadi 2015) (amongst others). All authors disagree with this editorial expression of concern.

\section{References}

Mohammadi K, Mostafaeipour A, Sedaghat A et al (2016) Application and economic viability of wind turbine installation in Lutak, Iran. Environ Earth Sci 75:248. https://doi.org/10.1007/s1266 5-015-5054-7

Mostafaeipour A, Mohammadi K (2015) In: Industrial engineering and operations management (IEOM) conference proceedings. https:// doi.org/10.1109/IEOM.2015.7093791

Publisher's Note Springer Nature remains neutral with regard to jurisdictional claims in published maps and institutional affiliations.
The original article can be found online at https://doi.org/10.1007/ s12665-015-5054-7.

Shahaboddin Shamshirband

shamshirband@um.edu.my

Kasra Mohammadi

kmohammadi@umass.edu

1 Department of Mechanical and Industrial Engineering, University of Massachusetts, Amherst, MA 01003, USA

2 Industrial Engineering Department, Yazd University, Yazd, Iran

3 Department of Mechanical Engineering, Isfahan University of Technology, Isfahan 84156-83111, Iran

4 Department of Computer System and Technology, Faculty of Computer Science and Information Technology, University of Malaya, 50603 Kuala Lumpur, Malaysia

5 